\title{
Indicações Geográficas como estratégia de desenvolvimento: o caso do Norte Pioneiro do Paraná ${ }^{1}$
}

\author{
Geographical Indications as a development strategy: the case of Norte \\ Pioneiro do Paraná
}
Indications géographiques en tant que stratégie de développement: le cas de Norte Pioneiro do Paraná
Las indicaciones geográficas como estrategia de desarrollo: el caso de Norte Pioneiro do Paraná

\author{
Mara Elena Bereta de Godoi Pereira² \\ Ana Elisa Bressan Smith Lourenzani ${ }^{2}$ \\ Kassia Watanabe ${ }^{3}$
}

\begin{abstract}
Recebido em 10/07/2017; revisado e aprovado em 01/10/2017; aceito em 01/11/2017
DOI: http://dx.doi.org/10.20435/inter.v19i3.1654
\end{abstract}

\begin{abstract}
Resumo: A Indicação Geográfica (IG) é uma estratégia relevante tanto para as firmas quanto para o desenvolvimento. Buscando descrever a coordenação entre os atores sociais que compõem o território da IG Norte Pioneiro do Paraná, em especial a participação da agricultura familiar, esta pesquisa demonstrou que a IG favoreceu a valorização do território e da atividade cafeeira, acesso a canais de comercialização e ações coletivas, contribuindo assim para o desenvolvimento.
\end{abstract}

Palavras-chave: desenvolvimento; Indicações Geográficas; agricultura familiar.

Abstract: Geographical Indication (GI) is a relevant strategy for firms and for the development of a territory. Aiming at understanding the coordination among social actors within the territory of the Norte Pioneiro do Paraná, this research demonstrated that the Gl contributes to development as it encourages joining efforts to develop the territory, valuing coffee production, accessing segmented markets and collective actions.

Keywords: development; Geographical Indications; family farm.

Résumé: L'indication géographique (IG) est une stratégie pertinente pour les entreprises et le développement. Afin de décrire la coordination entre les acteurs sociaux qui composent le territoire du Pioneiro Nord du Paraná, notamment la participation de l'agriculture familiale, cette recherche a démontré que l'IG favorisait la valorisation du territoire et l'activité caféière, l'accès aux canaux de commercialisation et aux actions contribuer au développement.

Mots-clés: développement; Indications Géographiques; agriculture familiale.

Resumen: La Indicación Geográfica (IG) es una estrategia relevante para las empresas y para el desarrollo de un territorio. Con el objetivo de comprender la coordinación entre los actores sociales en el territorio del Norte Pioneiro do Paraná, esta investigación demostró que el IG contribuye al desarrollo ya que fomenta la unión de esfuerzos para desarrollar el territorio, valorar la producción de café, acceder a mercados segmentados y acciones colectivas.

Palabras clave: desarrollo; las Indicaciones Geográficas; agricultura familiar.

\section{INTRODUÇÃO}

Indicações Geográficas (IGs) são registros concedidos a produtos ou serviços cujo reconhecimento e reputação estão atrelados à sua origem geográfica, seja pelas condições edafoclimáticas de uma determinada região, seja pelas tradições e saber-fazer típico, não permitindo que estes

\footnotetext{
${ }^{1}$ O presente artigo é parte dos resultados de dissertação de mestrado.

${ }^{2}$ Universidade Estadual Paulista (UNESP), Tupã, São Paulo, Brasil.

${ }^{3}$ Universidade Federal do Recôncavo da Bahia (UFRB), Cruz das Almas, Bahia, Brasil.
} 
sejam reproduzido em outro local (NIEDERLE, 2009; BRASIL, 2010). Segundo Cerdan (2013), as IGs surgiram quando produtores e consumidores passaram a reconhecer que um determinado produto se distinguia dos demais, dada a sua ligação inerente às condições climáticas, culturais e o saber-fazer local.

Com o aumento da valorização de produtos por sua qualidade, autenticidade, local de origem, entre outros, por parte do consumidor (LIKOUDIS et al., 2016), há também maior necessidade de regulamentação das IGs, tanto em âmbito nacional como internacional. De acordo com a World Intellectual Property Organization (WIPO), as IGs atestam que um produto tem um local específico de origem e apresenta qualidade ou reputação ligada a esse local. Isso permite àqueles que têm o direito de usar a IG, impedir a sua utilização por um terceiro cujo produto não está em conformidade com as normas aplicáveis ou está fora do território. As IGs são protegidas em diferentes países com diferentes tradições jurídicas, condições históricas e econômicas (WIPO, s.d.).

A regulação das IGs e sua proteção têm sido discutidas desde o século XIX e se tornadas cada vez mais importantes à medida que o comércio é feito no mundo globalizado (WIPO, s.d.). Entre exemplos de acordos regulados pelo WIPO e pela Organização Mundial do Comércio (OMC) estão: a Convenção da Paris; o Acordo de Madrid; o Acordo de Lisboa e o Acordo ADIPIC/TRIPs ${ }^{4}$. Muito embora, o ADIPIC/TRIPS não seja uma tentativa de uniformização da regulação da propriedade industrial iniciada por blocos de países, esse Acordo representa a primeira tentativa de harmonização mundial dos institutos de Propriedade Industrial. O parágrafo 2ํㅡㄹ do artigo 22 desse Acordo prevê que os membros poderão estabelecer legislação própria para efetivar a proteção desses territórios (BRASIL, 1994).

Para regulamentar o uso das IGs no Brasil, foi criada, em 1996, a Lei n. 9.279, que regula os direitos e as obrigações relativos à propriedade industrial. Segundo essa Lei, o registro de IG é concedido no país pelo Instituto Nacional da Propriedade Industrial (INPI) às entidades representativas da coletividade do território em questão (BRASIL, 1996). As IGs brasileiras são divididas em duas categorias: a) Indicação de procedência (IP): que indica o nome de determinada região geográfica reconhecida pela produção ou fabricação de determinado produto ou prestação de determinado serviço; b) Denominação de origem (DO): que indica o nome de determinada região geográfica cujo produto ou serviço se deva essencialmente ao meio geográfico, incluindo os fatores humanos e naturais.

As IGs proporcionam agregação de valor aos produtos, proteção da região produtora, proteção do saber-fazer tradicional e da herança histórico-cultural, além de proteger a região de ações oportunistas e falsificações (NIEDERLE, 2012; GIESBRECHT et al., 2014). Ressalta-se que é uma estratégia que tem o potencial de beneficiar todos os agentes envolvidos em um determinado território, inclusive a agricultura familiar.

A agricultura familiar caracteriza-se por uma produção diversificada e em pequenos lotes. Segundo Buainain, Romeiro e Guanziroli (2003), isto pode vir a ser um trunfo por reduzir custos e incertezas inerentes à comercialização. Os autores ressaltam que a diferenciação também pode ser utilizada como ferramenta para fortalecimento e geração de renda, considerando a demanda por produtos de qualidade reconhecida. Cerdan (2013) considera que os registros IGs são potenciais instrumentos de promoção da agricultura familiar, dada à possibilidade de qualificar

\footnotetext{
${ }^{4}$ Acordo sobre os Direitos de Propriedade Intelectual Relativos ao Comércio.
} 
e valorizar um produto, sobretudo em regiões que se destacam pela notoriedade desse produto e que necessitam desenvolver-se localmente.

Estudos demonstraram que benefícios e desafios foram percebidos em territórios com IG no Brasil. No Vale dos Vinhedos ${ }^{5}$, a IG proporcionou benefícios como o reconhecimento da região, criação de valor para o setor de turismo, fortalecimento do comércio local e geração de empregos, aumento do valor da terra, preocupação com a preservação do meio ambiente e com o embelezamento das propriedades rurais (SCHMIDT; SAES; MONTEIRO, 2014). Já na região do Pampa Gaúcho da Campanha Meridional, que recebeu o registro de IG para a carne bovina e seus derivados, estudos demonstram que os atores são, em sua maioria, grandes pecuaristas e que essa estratégia está voltada para um segmento do mercado de alimentos com altos padrões determinados, levando à exclusão dos pequenos produtores familiares nos ganhos obtidos por meio da IG (FROEHLICH et al., 2010; CHAMPREDONDE et al., 2014).

Buscando verificar como a coordenação entre os atores sociais e os seus resultados colaboram para o desenvolvimento local em territórios com IG, optou-se por analisar os registros para o café nesta pesquisa. No Brasil, há cinco regiões protegidas com este registro: Cerrado Mineiro; Serra da Mantiqueira de Minas Gerais; Norte Pioneiro do Paraná; Alta Mogiana em São Paulo; e Região de Pinhal, em São Paulo (INPI, s.d.).

O café foi objeto deste estudo devido à sua importância econômica e social na história do país e ao aumento do consumo de cafés diferenciados. O Brasil é o maior produtor e exportador de café mundial, contudo não obtém os potenciais ganhos, pois a exportação está concentrada em café verde e recebe um preço menor no mercado. Para superar essa dificuldade, o país tem buscado melhorar sua posição na exportação de café torrado e moído e acessando o mercado de cafés especiais (ORTEGA; JESUS, 2012).

Cafés especiais são aqueles que se diferenciam dos convencionais por meio dos atributos de qualidade. Esses atributos podem estar relacionados às características físicas, como origem, variedade, cor e tamanho, ou também ligados às questões de ordem ambiental e social, modo de produção ou condições de trabalho, e consistem em fontes de valor para estratégias de diferenciação. Segundo Pereira (2016), a metodologia elaborada pela Specialty Coffee Association of America (SCAA) é a mais utilizada no mercado, influenciando fortemente a dinâmica deste e determinando as estratégias e as decisões dos atores que o compõem.

Com base em Porter (1986) e Hitt, Ireland e Hoskisson (2003), a estratégia de diferenciação pode ser compreendida como investimentos contínuos na criação e desenvolvimento de características que diferenciam um bem ou serviço em formas que o cliente valoriza, atendendo assim às necessidades únicas dos clientes. Verifica-se que os consumidores estão demandando por produtos de alto valor agregado com características específicas, formando um mercado segmentado (ZYLBERSZTAJN et al., 2001; SPERS; SAES; SOUZA, 2004; NIEDERHAUSER et al., 2008; LIKOUDIS et al., 2016). A estratégia de diferenciação pode estar relacionada aos atributos de qualidade da bebida, origens e às questões ambientais e sociais. Assim, os cafés especiais englobam padrões de produto e de processo. A IG é uma forma de sinalização desses processos (ZYLBERSTAJN et al., 2001; SAES, SPERS, 2006).

A percepção pela origem do produto proliferou no mercado globalizado, e estes consumidores estão dispostos a pagar um prêmio para consumir os produtos que tenham suas verdadeiras

\footnotetext{
${ }_{5}^{5}$ Primeira região brasileira a receber o registro de IG na categoria Indicação de Procedência para vinho tinto, branco e espumante.
} 
raízes e possuam a qualidade original ao invés dos produtos padronizados (CAFAGGI et al., 2012; LIKOUDIS et al., 2016). A diferenciação do café por meio do uso da certificação e de registros de origem, pode contribuir para o acesso aos mercados desde que os produtores sejam capazes de cumprir os requisitos estabelecidos. Contudo, para que este acesso seja eficaz, é importante haver confiança entre os diversos atores sociais que o compõem, permitindo assim, o compartilhamento de conhecimento e, consequentemente, a coordenação da cadeia agroalimentar (AMBROSINI; FILIPPI; MIGUEL, 2008). Além disso, de acordo com Fernández-Barcala, GonzálezDíaz e Raynaud (2017), quando a garantia de origem é utilizada, como em uma IG, é necessário que haja uma governança pública que regule e promova a cooperação e preserve seu valor ao longo da cadeia produtiva. Tal governança deve ser complementada por uma governança interna em que os sistemas de controle de qualidade assegurem o atendimento às necessidades das transações orientadas para o mercado. Essa afirmação está alinhada à abordagem dos Sistemas Agroalimentares Localizados (SIAL). Para o SIAL, a coordenação dos atores sociais é um ponto chave para a organização. Um produto oriundo de um SIAL pode transmitir ao consumidor informações inerentes ao território, tais como a identidade e valorização do saber-fazer e da cultura local, do resgate da história local, da paisagem, da preocupação com o meio-ambiente, o que o torna um ativo com especificidade territorial (AMBROSINI; FILIPPI; MIGUEL, 2008). Ao considerar as interações entre as pessoas, o ambiente, as instituições, o saber-fazer e o consumo de alimentos, esta abordagem busca promover o desenvolvimento econômico, rural e social em regiões específicas (LOURENZANI; BANKUTI; PETERSON, 2013). A abordagem do SIAL pressupõe análises que vão além da lógica econômica, considerando aspectos sociais como identidade com o local, raízes históricas, tipo de produção única e oferta de produtos artesanais únicos que podem contribuir para o crescimento e desenvolvimento local (MUCHNIK, 2009).

Niederle (2009) afirma que para ser um instrumento de desenvolvimento territorial, a IG deverá formar uma rede entre os diversos atores que compõem o território. Segundo o autor, se ocorrer cooperação entre os diversos atores e o fluxo de informações entre estes for livre, todos serão beneficiados, e o território será desenvolvido.

Assim, as IGs podem ser consideradas tanto uma estratégia da firma, quando esta busca alocar recursos e capacidades para a geração de valor percebido pelo cliente, como uma estratégia de desenvolvimento. De acordo com Bowen (2010), as IGs são estratégias com potencial de desenvolvimento uma vez que valorizam a singularidade e a tradição de um determinado território. No entanto a autora chama atenção para a importância das instituições para regular e garantir a proteção de atores locais e territórios. Já Belletti e Marescotti (2011) consideram que os produtos com origem protegida exercem influência positiva sobre diferentes aspectos do desenvolvimento como: sistema econômico local; meio ambiente; paisagem; biodiversidade; cultura; identidade regional, entre outros.

Diante do exposto, o objetivo desta pesquisa é descrever a coordenação entre os atores sociais, em especial no que se refere à participação da agricultura familiar, no território do Norte Pioneiro do Paraná. Para tanto, buscou-se: a) caracterizar este território quanto ao ambiente físico, saber-fazer e tradição histórica; e b) identificar a contribuição das IGs para a coordenação horizontal entre os atores que compõem o território, considerando as dimensões identidade territorial, papel do estado, interação com o mercado e integração socioeconômica.

A primeira parte deste artigo traz a introdução com o referencial teórico que embasou a pesquisa, sua problemática e objetivo. A metodologia utilizada é descrita na segunda parte. Os 
resultados obtidos são discutidos na terceira parte, e as conclusões e sugestões para pesquisas futuras encerram a quarta e última parte.

\section{METODOLOGIA}

Para alcançar o objetivo proposto, foi realizada uma pesquisa descritiva de abordagem qualitativa. Cervo, Bervian e Silva (2007) consideram que a pesquisa descritiva é utilizada quando se busca conhecer as relações existentes e demais aspectos do comportamento humano, seja indivíduo, seja grupo social. Para tanto, os dados e os fatos observados neste tipo de pesquisa são colhidos na própria realidade sem manipulá-los, visando alcançar-lhe os objetivos, complementam os autores.

De acordo com Barjolle, Paus e Perret (2009), o método utilizado nesta pesquisa se enquadra como objetivo, pois fornecem um panorama dos efeitos da IG sobre um território. A estrutura teórico-conceitual se baseou na abordagem do SIAL, e os constructos utilizados foram: identidade territorial (ROCA; MOURÃO, 2003); papel do Estado como regulador de mercado (CAZELLA, 2011; MEDINA et al., 2015); integração entre produtores e mercado (ABRAMOVAY, 2003; MEDINA et al., 2015); integração socioeconômica (ABRAMOVAY, 2003; CAZELLA, 2011; MEDINA et al., 2015).

Um estudo de caso foi realizado no território pesquisado no mês de fevereiro de 2015. Segundo Gil (2002), o estudo de caso em pesquisas descritivas permite descobrir as razões de determinado fenômeno. Foram aplicados formulários aos presidentes da Associação dos Cafés Especiais do Norte Pioneiro do Paraná (ACENPP) e da Cooperativa dos Produtores de Cafés Certificados e Especiais do Norte Pioneiro do Paraná (COCENPP), aos agentes do Serviço Brasileiro de Apoio às Micros e Pequenas Empresas (SEBRAE) e a cinco agricultores familiares indicados pela Associação. Apesar do número reduzido de agricultores familiares entrevistados, realizaram-se as entrevistas até alcançar a saturação dos dados coletados.

\section{RESULTADOS E DISCUSSÕES}

\subsection{Caracterização do território}

O registro de IG do Norte Pioneiro do Paraná foi requerido pela ACENPP no ano de 2009 e obteve a concessão de Indicação de Procedência (IP) em 2012. O território compreende 45 municípios das regiões administrativas do Estado do Paraná, denominadas Norte Pioneiro do Paraná e Norte do Paraná, representadas por duas Associações de Prefeituras Municipais: Associação de Municípios do Norte Pioneiro do Paraná (AMUNORPI), que abrange 26 municípios; e Associação dos Municípios do Norte do Paraná (AMUNOP), que abrange 19 municípios (INPI, s.d.). Na região, encontram-se 7.500 produtores de café que cultivam a variedade Coffea arabica.

O registro de IG é concedido tanto para o café verde em grão, como para o industrializado torrado em grãos e/ou moído. Verifica-se que os requisitos a serem atendidos para alcançar a concessão do uso do registro preveem duas faixas de classificação para café verde em grão e/ou o café industrializado. No caso do café verde em grão, objeto deste trabalho, a pontuação a ser alcançada na bebida deverá ser de, no mínimo, 60 pontos para café superior e de 80 pontos para café especial, segundo a metodologia SCAA. Além desse requisito, há outras exigências relacionadas à classificação do lote, armazenamento, rastreabilidade e segurança alimentar, responsabilidade social e responsabilidade ambiental. O Quadro 1 traz a síntese dos requisitos para esta IG. 
Quadro 1 - Síntese dos requisitos para concessão do uso do registro de IG do Norte Pioneiro do Paraná

\begin{tabular}{|l|l|l|}
\hline IG & \multicolumn{1}{|c|}{ Descrição } \\
\hline Produto & Café verde em grão e industrializado torrado em grão e ou moído \\
\hline Espécie cultivada & \multicolumn{1}{|c|}{ Coffea arabica } \\
\hline \multirow{5}{*}{ Classificação do lote } & $\begin{array}{l}\text { Café em grão verde - tipo igual ou } \\
\text { inferior a 4 (no máximo 26 defeitos) } \\
\text { para o café especial e tipo igual ou } \\
\text { inferior a 6 (no máximo 86 defeitos) } \\
\text { para o café superior }\end{array}$ & $\begin{array}{l}\text { Café industrializado - a) Gourmet: } \\
\text { para cafés em grão verde, adquiridos } \\
\text { com a classificação "Café Especial"; } \\
\text { b) Superior: para cafés em grão } \\
\text { verde, adquiridos com a classificação } \\
\text { "Café Superior". }\end{array}$ \\
\hline Classificação da bebida & $\begin{array}{l}\text { Café especial: mínimo de 80 pontos } \\
\text { metodologia SCAA }\end{array}$ & $\begin{array}{l}\text { Café Gourmet: 7,3 pontos na } \\
\text { Café superior: mínimo de 60 pontos } \\
\text { metodologicação do PQC }\end{array}$ \\
\hline Depósito do lote & $\begin{array}{l}\text { Café Superior: nota igual ou superior } \\
\text { a 6 pontos na classificação do PQC. }\end{array}$ \\
\hline Outros requisitos & $\begin{array}{l}\text { Rastreabilidade e segurança alimentar, responsabilidade social e } \\
\text { responsabilidade ambiental. }\end{array}$ \\
\hline
\end{tabular}

* Programa de Qualidade do Café da ABIC.

Fonte: Elaborado pelas autoras com base em INPI (s.d.).

A variação de pontuação para café superior e especial pode ser explicada pelo fato de a região do Norte Pioneiro do Paraná estar sobre duas regiões de planaltos separados por uma escarpa, e apresentando uma variedade de tipos de solo. Os mais férteis são do tipo terra roxa, com elevada fertilidade natural. A região também apresenta dois tipos de clima: o Subtropical Úmido Mesotérmico, com verões quentes, geadas pouco frequentes e chuvas com tendência de concentração nos meses de verão, apresentando temperatura média anual de $21^{\circ} \mathrm{C}$; e o Subtropical Úmido Mesotérmico, com verões frescos e geadas severas e frequentes, sem estação seca e temperatura média anual de $19^{\circ} \mathrm{C}$ (INSTITUTO PARANAENSE DE DESENVOLVIMENTO ECONÔMICO E SOCIAL [IPARDES], 2004). Assim, há condições edafoclimáticas que permitem o desenvolvimento de diversos tipos e de diferentes patamares de qualidade para o café.

A ocupação da região teve início em meados do século XIX com a instalação de grandes propriedades dedicadas ao cultivo do café. Com a consolidação do cultivo, a economia da região foi dinamizada e novas cidades surgiram. Contudo, com o declínio do mercado devido à Crise de 1929 e a erradicação de pés de café, a cultura cedeu área para pastagens e outras culturas, tais como milho, arroz, algodão, feijão, cana-de-açúcar, entre outros. Outro fator que colaborou para a substituição da cultura foi a intensa geada no estado em 1975, que dizimou os pés de café existentes (WINKLER; SOUZA, 2012).

A crise da cultura do café impactou na dinâmica demográfica por meio do êxodo rural. Também houve a concentração de terras, sendo que o segmento que mais apresentou redução de estabelecimentos foi o da agricultura familiar com perda de 24,16\% no período de 1985 a 1995 (IPARDES, 2004). Apesar de todas essas dificuldades apresentadas e da redução da área destinada ao cultivo do café, a região ainda se mantinha como a principal produtora de café no estado do Paraná, com predomínio da produção de café commodity, mas também existe a produção de café especial (BRONZERI, 2009).

Em 2006, com o apoio do SEBRAE, do Sistema Federação da Agricultura do Estado do Paraná (FAEP) e do Instituto Paranaense de Assistência Técnica e Extensão Rural (EMATER), foi lançado 
o Programa Cafés Especiais do Norte do Paraná. Seu objetivo era estimular a produção de cafés especiais, divulgar a região como tradicional produtora de café e organizar os produtores em ações coletivas, a fim de obter certificações, inovações tecnológicas, melhoria de gestão e desenvolvimento territorial (LOURENZANI; BANKUTI; PETERSON, 2013). Considerando a abordagem $\mathrm{SIAL}$, verifica-se que esse Programa busca ativar o território na medida em que identificou um recurso cuja qualidade está vinculada às características do território, sobretudo relacionadas à tradição, e abrangendo aos atores sociais pertencentes a ele (MUCHNIK, 2006; 2009).

Para alcançar o objetivo do Programa, em 2008 foi fundada a ACENPP. A movimentação para o desenvolvimento do café especial foi possível pelos esforços da ACENPP (BRONZERI; BULGACOV, 2014). Anterior à criação da ACENPP, foi instituído o Concurso Qualidade Paraná para melhorar a imagem do café paranaense, valorizar o produto e buscar visibilidade no mercado. Esse concurso foi instituído pelo Governo do Paraná, de acordo com a Resolução SEAB n. 194/96 e é organizado pela Secretaria do Estado da Agricultura e do Abastecimento do Paraná (SEAB) e coordenado pela Câmara Setorial do Café do Estado do Paraná (VOIGT-GAIR; MIGLIORANZA; FONSECA, 2013).

A ACENPP está dividida em 12 núcleos, visando a favorecer o alcance dos seus objetivos, pois é possível identificar e atender as necessidades particulares de cada núcleo. Cada núcleo que compõe a ACENPP pode formar a sua própria associação. Foi observado que há núcleos mais ativos, como o de Lavrinha/Pinhalão, Tomazina/Matão e São Jeronimo da Serra, que, por meio da coletividade, buscam reduzir custos na aquisição de máquinas e insumos e, assim, aumentar a qualidade e a produtividade da lavoura (INOVAÇÃO..., 2015). A ACENPP realiza reuniões mensais com a participação de dois representantes de cada núcleo, consultores do SEBRAE e agrônomos do Programa 100\% Qualidade, alinhando as necessidades de cada núcleo às decisões tomadas para o território. Em 2011, foi fundada a COCENPP com o objetivo de comercializar o café especial produzido na região.

Considerando a abordagem SIAL, verifica-se que a qualidade do café produzido nessa região está mais fortemente atrelada à tradição secular do território do que às condições edafoclimáticas. Verifica-se também que os atores sociais do território têm realizado esforços na tentativa de promover o desenvolvimento por meio do reconhecimento do café como produto notório pela qualidade e reputação. Muchnik (2009) afirma que esses aspectos contribuem para a análise do desenvolvimento local segundo a abordagem SIAL. Logo, é importante analisar o desenvolvimento do território segundo a referida abordagem e verificar como o uso do registro de IG tem proporcionado a cooperação entre os diversos atores, promovendo o fluxo de informações e contribuindo para o desenvolvimento do território, como apontado por Niederle (2009).

\subsection{Desenvolvimento e identidade territorial}

Segundo Roca e Mourão (2003), a identidade territorial é o conjunto de elementos característicos e específicos de um determinado local, os quais, quando identificados, distinguem um determinado grupo social dos demais territórios. Essa relação de identidade leva a um sentimento de pertencimento ao território. A pesquisa de campo indicou que os entrevistados reconhecem que o café é um produto típico da região e se sentem orgulhosos quando essa referência é feita como produtor de café especial. Essa referência valoriza a produção dos agricultores e a imagem do produto, que, por muito tempo, foi considerado de baixa qualidade. Eles atribuem a alteração 
da imagem negativa ao Programa Cafés Especiais, o que contribuiu para o reconhecimento do território como produtor de café com qualidade e reputação, e posterior concessão do registro de IG.

Com relação ao desenvolvimento territorial, os entrevistados acreditam que os pontos de alavancagem são a adesão dos produtores de café ao Programa, a mudança da cultura existente de aversão à implantação de tecnologias para a melhoria da produção, e o oferecimento de assistência técnica adequada por parte do governo. Os entrevistados também acreditam que o turismo seja importante para a divulgação do café e valorização do território. No tocante às ações de turismo, há diversas atividades: um plano turístico, a "Rota do Café"; uma festa municipal no município de Ribeirão Claro, a Festa do Café de Ribeirão Claro (FESCAFÉ); e a Feira Internacional de Cafés Especiais do Norte Pioneiro do Paraná (FICAFÉ).

A "Rota do Café" abrange a região Norte do Paraná e, dos nove municípios que a compõem, três fazem parte do território do Norte Pioneiro do Paraná: Santa Mariana, Uraí e Ribeirão Claro. Criada em 2009, a rota é composta por 32 estabelecimentos, como cafeterias, museus com a temática do café, fazendas e sítios produtores, fazendas históricas que mantêm construções e acervo histórico da época áurea, pousadas, agroindústrias e restaurantes. De 2009 a 2015, a rota recebeu 6.500 visitantes brasileiros e estrangeiros. Em 2011, participou do Prêmio Casos de Sucesso do Programa de Regionalização do Turismo, realizado pelo Ministério do Turismo, alcançando o prêmio de melhor roteiro turístico do Brasil.

Outro evento realizado na região e que traz a temática do café é a FESCAFÉ, uma feira realizada anualmente no mês de julho, no município de Ribeirão Claro. Segundo os entrevistados, no início a feira tinha como objetivo a divulgação do café com exposições e negociações, contudo o foco tem sido a realização de grandes shows artísticos e rodeios. Já a FICAFÉ envolve todos os entrevistados no território e está direcionada a produtores, compradores e especialistas em café especial, recebendo visitantes do Brasil e do exterior. Ela é realizada na cidade de Jacarezinho, e sua programação prevê palestras, exposições de implementos agrícolas, clínicas tecnológicas voltadas para a produção e acessos a mercado, cursos de degustação, concurso de qualidade e rodadas de negócios.

Considerando a identidade territorial e as ações realizadas, verifica-se que, no Norte Pioneiro do Paraná, os atores buscam vincular a imagem do café a atividades festivas e de turismo. Segundo Requier-Desjardins (2007), essas ações, se mais bem articuladas e coordenadas, poderão fortalecer o sentimento de pertencimento ao território, contribuindo para o desenvolvimento deste, na medida em que o ativa e proporciona o fomento da economia local como um todo.

\subsection{O papel do Estado}

Segundo Cazella (2011), o Estado contribui para o desenvolvimento territorial na medida em que busca minimizar as falhas de mercado por meio de regulação e fornece apoio por meio de extensão. Medina et al. (2015) destacaram a atuação do Estado ao promover políticas públicas e garantir infraestrutura. No caso do Paraná, a obtenção do registro de IG teve importante apoio do Instituto Agronômico do Paraná (IAPAR), EMATER, SENAR e SEAB. O IAPAR também auxiliou na avaliação do café segundo a metodologia SCAA.

Em relação à capacitação de mão de obra e gerencial do agricultor familiar, o SENAR e o SEBRAE são citados pelos entrevistados. O Programa SEBRAE de Liderança proporcionou a eleição dos jovens agricultores familiares, presidentes da ACENPP e da COCENPP. A assistência técnica é 
garantida por meio do Programa 100\% Qualidade, desenvolvido pelo SEBRAE, e complementada pela parceria com o Instituto Federal do Sul de Minas, instituição pública de ensino superior federal.

O Programa 100\% Qualidade é desenvolvido por agrônomos contratados pelo SEBRAE que visitam as propriedades quinzenalmente, oferecendo assessoria técnica para fomentar a qualidade. Eles identificam os potenciais riscos e introduzem inovações tecnológicas por meio de novas técnicas de manejo e boas práticas na lavoura. Essas ações permitem melhoria da renda aos agricultores na medida em que há melhoria da produção e potencial de acessar novos mercados. A assistência técnica, as capacitações de mão de obra, de gerenciamento da propriedade e da produção são também importantes para alcançar e manter a qualidade do café. Uma vez alcançada a qualidade exigida, o agricultor familiar tem condições de acessar os mercados mais exigentes. Logo, o Estado exerceu importante papel de coordenação na obtenção do registro de IG, principalmente nas questões documentais, tão necessárias para o alcance do registro. Nesse caso, as instituições públicas como INPI, MAPA, EMATER, IAPAR, SEAB e SENAR foram essenciais para que os atores sociais alcançassem a concessão do uso do registro da IG.

\subsection{Integração entre os produtores e o mercado}

Abramovay (2003) e Medina et al. (2015) consideram que a integração entre o produtor e o mercado pode contribuir para o desenvolvimento do território. É importante ressaltar que os cafés de origem única e aqueles com registro de IG são classificados como cafés especiais e acessam esse nicho de mercado.

Durante as entrevistas, verificou-se que a produção de café especial no território é direcionada principalmente ao mercado externo. Isto é proporcionado pela concomitância de utilização de certificações de terceira parte como Fair Trade, UTZ Certified e Rainforest Alliance. Essas certificações são valorizadas pelos consumidores de países desenvolvidos, dado o apelo social e ambiental que estas buscam garantir.

Um importante canal de comercialização e de marketing para o café especial é o Cup of Excellence, concurso que premia os melhores lotes de café no país e que, após a premiação, são leiloados por altos valores se comparado ao preço do café commodity. Em 2015, o território do Norte Pioneiro do Paraná enviou, pela primeira vez, amostras para o Cup of Excellence - Pulped Naturals, e teve três amostras premiadas. Espera-se com essas premiações a valorização dos lotes por meio dos lances realizados no leilão, e mais visibilidade do território perante as importadoras e cafeterias. Além disso, a FICAFE tem proporcionado ao Norte Pioneiro Paranaense o contato com os compradores de cafés especiais. A programação dessa feira também prevê a realização do Concurso de Qualidade Sabores do Norte Pioneiro do Paraná, que realiza um leilão após o término do concurso, proporcionando visibilidade à região.

A pesquisa permitiu observar que os agricultores familiares estão se especializando na produção de café especial, o que tem possibilitado a inserção em outros mercados, sobretudo os mercados segmentados e os nichos de mercados, importantes estratégias para o desenvolvimento tratadas por Medina et al. (2015).

\subsection{Integração socioeconômica}

Segundo a abordagem SIAL, para alcançar o desenvolvimento de um território, é necessário que haja a interação entre os diversos atores sociais que o compõem, buscando identificar 
quais recursos poderiam ser ativados e estrategicamente utilizados para alavancá-lo (SPECHT; RÜCKERT, 2008; CAZELLA, 2011; BOUCHER, 2012).

Considerando a importância da integração socioeconômica por meio de cooperação e ações coletivas, buscou-se analisar o papel da associação e da cooperativa na coordenação dos atores no Norte Pioneiro do Paraná. Verificou-se que a ACENPP e a COCENPP atuam conjuntamente para alavancar a produção e comercialização de café especial. Todos os entrevistados consideraram que a participação nas reuniões da Associação, o respeito entre os envolvidos na produção do café e a interação com os produtores são bons e melhoraram com a implantação da IG. A ACENPP oferece aos associados cursos de capacitação segundo critérios da SCAA, para degustar café e controlar a qualidade, de formação de líderes, e de práticas agrícolas para alcançar as certificações. Tudo isso com apoio do SEBRAE, do IF do Sul de Minas, do SENAR, dentre outras instituições. Além disso, a Associação é quem fornece o selo da IG, caso a produção atinja os requisitos estabelecidos no protocolo de uso.

Durante a realização da pesquisa de campo, verificou-se que, no território do Norte Pioneiro do Paraná, há forte atuação da agricultura familiar na associação e na cooperativa. Ambos os presidentes da associação e da cooperativa são agricultores familiares, e os demais são motivados a participarem dos núcleos que compõem a ACENPP, com atuação efetiva nas decisões e planejamentos para o território.

Quanto à relação com as torrefadoras, a Associação informou que pretende iniciar a comercialização com o registro de IG por meio do café torrado e moído. Ela deverá fornecer o selo mediante a quantidade de café transacionado com a torrefadora. Contudo isto é um planejamento para longo prazo.

Observa-se que, entre os atores sociais que compõem o território, há o compartilhamento de informações e de valores, das implantações de inovações tecnológicas, a valorização das potencialidades do território, ou seja, do saber-fazer, da cultura, da história e meio ambiente. Essas características fortalecem as ações coletivas e a identidade territorial, na medida em que os atores sociais buscam alcançar os interesses comuns a eles, e o resultado dessa ação impacta no desenvolvimento do território.

\section{CONCLUSÕES}

Esta pesquisa teve como objetivo principal descrever a coordenação entre os atores sociais, em especial no que se refere à participação da agricultura familiar, no território do Norte Pioneiro do Paraná, analisando as IGs como estratégias de desenvolvimento. No que tange à caracterização do território, conclui-se que este se desenvolveu por meio do cultivo do café, por isto a forte tradição histórica. Além disto, apresenta condições edafoclimáticas favoráveis a esse cultivo.

Os atores sociais presentes no território se identificam com a produção do café e se sentem orgulhosos por produzirem um produto cuja qualidade lhe confere o status de café especial. Além disto, verificou-se, durante a pesquisa, que a ação coletiva tem permitido a redução da assimetria da informação, na medida em que compartilham do conhecimento gerado. Verificouse também que há uma forte preocupação em capacitar e inserir os agricultores familiares no mercado de cafés especiais.

O Estado, nesse caso, tem sido um importante elo de coordenação entre os atores do território pesquisado na medida em que apoia e regula as atividades desenvolvidas para alcançar e manter a concessão do uso do registro de IG. 
Os resultados indicam que a IG foi uma ação resultante da organização dos atores sociais do território, o que resultou em ganhos que vão além da esfera econômica, como a estratégia de diferenciação proporciona. Os resultados estão também no desenvolvimento territorial, considerando a valorização do território e da atividade cafeeira, as ações coletivas e a coordenação dos agentes. Tal resultado é importante considerando que Barjolle, Paus e Parret (2009), ao analisarem diferentes estudos de impactos das IGs nos territórios, verificaram que estes estão ligados principalmente a fatores socioeconômicos, carecendo maior enfoque na produção sustentável e no desenvolvimento rural.

A limitação desta pesquisa está na dificuldade de mensuração dos benefícios provenientes da IG e do método do estudo de caso. Sugere-se em pesquisas futuras que estas sejam realizadas com um maior número de entrevistados.

\section{REFERÊNCIAS}

ABRAMOVAY, R. O futuro das regiões rurais. Porto Alegre: Editora da UFRGS, 2003.

AMBROSINI, L. B.; FILIPPI, E. E.; MIGUEL, L. de A. SIAL: análise da produção agroalimentar a partir de um aporte territorialista e multidisciplinar. Revista Interfaces em Desenvolvimento, Agricultura e Sociedade, Rio de Janeiro, RJ, v. 2, n. 1, p. 6-31, jan./jun. 2008.

BARJOLLE, D.; PAUS, M.; PERRET, A. Impacts of Geographical Indications review of methods and empirical evidences. International Association of Agricultural Economistis Conference, Beijing, China, 16-22 aug. 2009.

BELLETTI, G.; MARESCOTTI, A. Origin products, geographical indications and rural development. In: BARHAM, E.; SYLVANDER, B. (Ed.). Labels of origin for food: local development, global recognition. London, UK: CAB International, 2011.

BOUCHER, F. De la AIR a los SIAL: reflexiones, retos y desafíos en América Latina. Agroalimentaria, v. 18, n. 34, p. 79-90, enero/junio 2012.

BOWEN, S. Embedding local places in global spaces: geographical indications as a territorial development strategy. Rural Sociology, v. 75, n. 2, p. 209-43, jun. 2010.

BRASIL. Ministério da Agricultura, Pecuária e Abastecimento. Curso de propriedade intelectual \& inovação no agronegócio: Módulo II, indicação geográfica. Brasília: MAPA; Florianópolis: SEaD/UFSC/FAPEU, 2010.

Lei n. 9.279, de 14 de maio de 1996. Regula direitos e obrigações relativos à propriedade industrial. Disponível em: <http://www.planalto.gov.br/ccivil_03/leis/L9279.htm>. Acesso em: 13 abr. 2017.

Decreto n. 1.355, de 30 de dezembro de 1994. Promulgo a Ata Final que Incorpora os Resultados da Rodada Uruguai de Negociações Comerciais Multilaterais do GATT. Disponível em: <http://www.planalto. gov.br/ccivil_03/decreto/Antigos/D1355.htm>. Acesso em: 13 abr. 2017.

BRONZERI, M. S. A influência das estratégias competitivas e colaborativas da cadeia produtiva do café no conteúdo estratégico das empresas e produtores do Norte Pioneiro do Paraná. 2009. 194p. Dissertação (Mestrado em Administração)- Universidade Federal do Paraná (UFPR), Curitiba, 2009.

BRONZERI, M. S.; BULGACOV, S. Estratégias na cadeia produtiva do café no Norte Pioneiro do Paraná: competição, colaboração e conteúdo estratégico. Organizações Rurais \& Agroindustriais, Lavras, MG, v. 16, n. 1, p. 77-91, 2014.

BUAINAIN, A. M.; ROMEIRO, A. R.; GUANZIROLI, C. Agricultura familiar e o novo mundo rural. Sociologias, Porto Alegre, v. 5, n. 10, p. 312-47, jul./dez. 2003.

CAFAGGI, F. et al. Accessing the global value chain in a changing institutional environment: comparing aeronautics and coffee. IDB Working Paper, series-370, 2012. 
CAZELLA, A. A. As bases sociopolíticas do desenvolvimento territorial: uma análise a partir da experiência francesa. In: FROEHLICH, J. M. (Org.). Desenvolvimento territorial: produção, identidade e consumo. Ijuí: Editora Unijuí, 2011. Parte I, p. 15-52.

CERDAN, C. Indicações geográficas e estratégias de desenvolvimento territorial. In: NIEDERLE, P. A. (Org.). Indicações geográficas: qualidade e origem dos mercados alimentares. Porto Alegre: Editora da UFRGS, 2013. Parte II, p. 125-50.

CERVO, A. L.; BERVIAN, P. A.; SILVA, R. Metodologia cientifica. São Paulo: Prentice Hall, 2007.

CHAMPREDONDE, M. et al. La pampa como indicación geográfica para diferenciar carnes vacunas em Argentina y en Brasil: motivaciones y limitantes. Agroalimentaria, v. 20, n. 38, p. 35-52, jan./jun. 2014.

FERNÁNDEZ-BARCALA, M.; GONZÁLEZ-DÍAZ, M.; RAYNAUD, E. Contrasting the governance of supply chains with and without geographical indications: complementarity between levels. Supply Chain Management: An International Journal, v. 22, n. 4, p. 305-20, 2017.

FROEHLICH, J. M. et al. A agricultura familiar e as experiências de Indicações Geográficas no Brasil meridional. Agrociencia Uruguay, v. 14, n. 2, p. 115-25, jul./dez. 2010.

GIL, A. C. Como elaborar projetos de pesquisa. São Paulo: Atlas, 2002.

GIESBRECHT, H. O. et al. Indicações geográficas brasileiras. Brasília: SEBRAE/INPI, 2014.

HITT, M. A.; IRELAND, R. D.; HOSKISSON, R. E. Administração estratégica. São Paulo: Bookman, 2003.

INOVAÇÃO e tecnologia: cafés especiais do Norte Pioneiro do Paraná. Jacarezinho: SEBRAE, ACENPP, COCENPP, 2015.

INSTITUTO NACIONAL DE PROPRIEDADE INDUSTRIAL (INPI). Pedidos de Indicação Geográfica concedidos e em andamento. [s.d.]. Disponível em: <http://www.inpi.gov.br/menu-servicos/indicacao-geografica/ pedidos-de-indicacao-geografica-no-brasil>. Acesso em: 19 abr. 2017.

INSTITUTO PARANAENSE DE DESENVOLVIMENTO ECONÔMICO E SOCIAL (IPARDES). Leituras regionais: Mesorregião Geográfica Norte Pioneiro Paranaense. Curitiba: IPARDES/BRDE, 2004.

LIKOUDIS, Z. et al. Consumers' intention to buy protected designation of origin and protected geographical indication foodstuffs: the case of Greece. International Journal of Consumer Studies, v. 40, n. 3, p. 283-9, maio 2016.

LOURENZANI, A. B. S.; BANKUTI, S. M. S.; PETERSON, H. H. Geographical indication and LAFS sustainability: evidences from specialty coffee from the Norte Pioneiro region in Brazil. In: CONGRESSO INTERNACIONAL SIAL, 6., Florianópolis, 2013. Disponível em: <https://www.researchgate.net/publication/284456378_ Geographical_indication_and_LAFS_sustainability_evidences_from_specialty_coofee_from_the_Norte_ Pioneiro_region_in_Brazils.

MEDINA, G. et al. Development conditions for family farming: lessons from Brazil. World Development, v. 74, p. 386-96, out. 2015.

MUCHNIK, J. Localised Agrifood Systems: concept development and diversity of situations. In: ANNUAL MEETINGS OF THE AGRICULTURE, FOOD, AND HUMAN VALUES. Proceedings... Pennsylvania: State College, 2009.

. Sistemas agroalimentarios localizados: evolución del concepto y diversidad de situaciones. In: CONGRESO INTERNACIONAL DE LA RED SIAL, 3., 2006, Baeza (Jaén), Espanha Sistemas Agroalimentarios Locales. Baeza, Espanha: ALTER6, 2006. Disponível em: <http://syal.agropolis.fr/ALTER06/pdf/actes/c14. pdf>. Acesso em: 4 set. 2014

NIEDERHAUSER, N. et al. Information and its management for differentiation of agricultural products: the example of specialty coffee. Computers and Eletronics in Agriculture, v. 61, n. 2, p. 241-53, maio 2008.

NIEDERLE, P. A. O mercado vitivinícola e a reorganização do sistema de indicações geográficas na região do Languedoc, França. Organizações Rurais \& Agroindustriais, Lavras, MG, v. 14, n. 2, p. 155-73, 2012. 
. Controvérsias sobre a noção de indicações geográficas enquanto Instrumento de desenvolvimento territorial: a experiência do vale dos Vinhedos em questão. In.: SOCIEDADE BRASILEIRA DE ECONOMIA, ADMINISTRAÇÃO E SOCIOLOGIA RURAL, 47., 2009. Porto Alegre. Anais... Porto Alegre, 2009.

ORTEGA, A. C.; JESUS, C. M. de. Café e território: a cafeicultura no Cerrado Mineiro. Campinas, SP: Alínea, 2012.

PEREIRA, M. E. B. G. Coordenação na agricultura familiar e desenvolvimento territorial: o caso das Indicações Geográficas para o café. 2016. 156 f. Dissertação (Mestrado em Agronegócio e Desenvolvimento) - Faculdade de Ciências e Engenharia, Universidade Estadual Paulista "Júlio de Mesquita Filho" (UNESP), Tupã, SP, 2016.

PORTER, M. E. Estratégia competitiva: técnicas para análise de indústrias e da concorrência. 7. ed. Rio de Janeiro: Elsevier, 1986.

REQUIER-DESJARDINS, D. Systèmes agroalimentaires localisés et qualification: une relation complexe. In: COLÓQUIO INTERNACIONAL SOBRE DESENVOLVIMENTO TERRITORIAL SUSTENTÁVEL. Anais... Florianópolis, Brasil, 2007. p. 12.

ROCA, Z.; MOURÃO, J. C. Identidade e desenvolvimento territorial entre a retórica e a prática. Revista de Humanidades e Tecnologias, n. 9, p. 102-10, 2003.

SAES, M. S. M.; SPERS, E. E. Percepção do consumidor sobre os atributos de diferenciação no segmento rural: café no mercado interno. Organizações Rurais \& Agroindustriais, Lavras, MG, v. 8, n. 3, p. 354-67, 2006.

SCHMIDT, C. M.; SAES, M. S. M.; MONTEIRO, G. F. A. Value creation and value appropriation in networks: an empirical analysis of the role of geographical indication in the wine industry in Vale dos Vinhedos, RS, Brazil. Organizações Rurais \& Agroindustriais, Lavras, MG, v. 16, n. 3, p. 343-62, 2014.

SPECHT, S.; RÜCKERT, A.A. Sistema Agroalimentar Local: uma abordagem para a análise da produção de morangos, no Vale do Caí, RS. In: CONGRESSO DA SOCIEDADE BRASILEIRA DE ECONOMIA, ADMINISTRAÇÃO E SOCIOLOGIA RURAL, 46, 2008. Rio Branco. Anais... Rio Branco: SOBER, 2008. Disponível em: <http:// www.ufrgs.br/pgdr/arquivos/656.pdf>. Acesso em: 4 set. 2014

SPERS, E. E.; SAES, M.S.M.; SOUZA, M.C.M. Análise das preferências do consumidor brasileiro de café: um estudo exploratório dos mercados de São Paulo e Belo Horizonte. Revista de Administração (RAUSP), n. 39, v.1, p. 53-61, jan./mar. 2004.

VOIGT-GAIR, L.; MIGLIORANZA, E.; FONSECA, I.C.B. A dinâmica do concurso "Café Qualidade Paraná" na produção de cafés especiais. Semina: Ciências Agrárias, Londrina, v. 34, n. 6, suplemento 1, p. 3173-80, 2013.

WINKLER, C. A. G.; SOUZA, J. P Condições de apropriação de renda no sistema agroindustrial do café. Caderno de Administração, Maringá, PR, v. 20, n. 2, p. 23-37, 2012.

WORLD INTELLECTUAL PROPERTY ORGANIZATION (WIPO). Geographical Indications. [s.d.]. Disponível em: <http://www.wipo.int/geo_indications/en/\#>. Acesso em: 6 out. 2017.

ZYLBERSZTAJN, D. et al. Diagnóstico sobre o sistema agroindustrial de cafés especiais e qualidade superior do estado de Minas Gerais. Relatório Final PENSA - FIA - FEA - USP, São Paulo, junho, 2001.

\section{Sobre as autoras:}

Mara Elena Bereta de Godoi Pereira: Assessora Administrativa da Diretoria, Faculdade de Ciências e Engenharia, UNESP/Câmpus Tupã. Graduada em Administração pela Faculdade de Ciências Contábeis e Administração de Tupã (FACCAT), mestre em Agronegócio e Desenvolvimento pela UNESP. E-mail: mara@tupa.unesp.br 
Ana Elisa Bressan Smith Lourenzani: Professora assistente doutora da Faculdade de Ciências e Engenharia da UNESP/Câmpus Tupã. Graduada em Agronomia pela Universidade Federal de Viçosa, mestrado e doutorado em Engenharia de Produção pela Universidade Federal de São Carlos e Pós-doutorado na Kansas State University. E-mail: anaelisa@tupa.unesp.br

Kassia Watanabe: Professora da Universidade Federal do Recôncavo da Bahia, UFRB. Graduada em Administração pela Fundação Armando Álvares Penteado e em Direito pela Universidade Presbiteriana Mackenzie e doutorado em Ciências Políticas pela Scuola Superiore Sant'Anna di Studi Universitari e Perfezionamento. E-mail: wtkassia@hotmail.com 